hippocampal volumes than controls with intact working memory. (Beauchamp $\mathrm{MH}$, Thompson DK, Howard K, et al. Preterm infant hippocampal volumes correlate with later working memory deficits. Brain Nov 2008;131:2986-2994). (Respond: Dr Peter J Anderson, School of Behavioural Science, The University of Melbourne, Melbourne, VIC 3010, Australia. E-mail: peterja( ( 2 unimelb.edu.au).

COMMENT. Children born preterm have smaller hippocampal volumes that correlate with working memory deficits measured at 2 years of age. Further research will determine the longterm effect of altered hippocampal volumes on cognitive function of premature infants.

\title{
NEUROGLIAL HETEROTOPIA AND NASOPHARYNGEAL OBSTRUCTION IN A NEONATE
}

The clinical presentation, imaging, treatment, and pathology of a case of neuroglial heterotopia in the nasopharynx causing airway obstruction in a newborn are reported from Columbus Children's Hospital, OH. MRI and CT showed a cystic mass filling the nasopharynx with a midline bony defect in the sphenoid bone above the clivus. Posterior nasal endoscopy visualized the cystic lesion prior to surgical removal. Connection with CSF and subarachnoid space was excluded. At 6-month follow-up, developmental miletones were normal, and repeat CT showed no evidence of recurrence of the mass. Histopathology of the lesion showed choroid plexus, glial, and respiratory-like epithelial cells. (Husein OF, Collins M, Kang DR. Neuroglial heterotopia causing neonatal airway obstruction: presentation, management, and literature review. Eur J Pediatr Dec 2008;167:1351-1355). (Respond: OF Husein, 1414 N Houk Rd, Suite 208, Spokane, WA 99216. E-mail: tiffhusein(a)yahoo.com).

COMMENT. Reviewing the literature, the authors found reports of 30 cases of pharyngeal neuroglial heterotopia. Both CT and MRI are recommended in the assessment of nasopharyngeal masses. CT visualizes any bony deformities of the skull base, and MRI detects intracranial connections through the skull defect. Encephalocele has a similar histology but differs from neuroglial heterotopia by maintaining a connection to the subarachnoid space.

\section{ATTENTION DEFICIT DISORDERS}

\section{NEUROANATOMICAL ABNORMALITIES IN ADOLESCENT ADHD}

Twenty-four adolescents with familial ADHD and 10 control youths underwent highresolution structural MRI, and frontal lobe gyri and caudate were compared in a study at Stanford University and other US centers. Youths with ADHD had larger right caudate and right inferior frontal lobe volumes than control subjects. An increase in left caudate volume in a subgroup of ADHD youths was correlated with decreasing functional activation in this region. The findings were thought to reflect neurodevelopmental changes specific to late adolescence in familial ADHD. (Garrett A, Penniman L, Epstein JN et al. Neuroanatomical abnormalities in adolescents with attention-deficit/hyperactivity disorder. J Am Acad Child 